\title{
Knowledge Acquisition and Administrative Employee Performance in Nigerian Universities
}

\author{
Christopher Akpotu ${ }^{1} \&$ Eebah Dumka Lebari ${ }^{2}$ \\ ${ }^{1}$ Department of Business Administration, Niger-Delta University, Wilberforce Island, Amassoma, Nigeria \\ ${ }^{2}$ Department of Management, University of Port Harcourt, Nigeria \\ Correspondence: Christopher Akpotu, Department of Business Administration, Niger-Delta University, \\ Wilberforce Island, Amassoma, Nigeria. E-mail: chrisakpotu4u@yahoo.com
}

Received: July 5, $2014 \quad$ Accepted: August 20, 2014 Online Published: November 26, 2014

doi:10.5539/jms.v4n4p116 URL: http://dx.doi.org/10.5539/jms.v4n4p116

\begin{abstract}
This paper examined the relationship between knowledge acquisition practices and performance of administrative employees in tertiary educational institutions in South-South Nigeria. The study had relied on a structured survey instrument adapted from existing literature and code named KAAEP-Q to obtain required data on the investigated phenomenon. This was served on the sample subjects that were selected through a random sampling exercise. The result from the analysed data showed a significant relationship between knowledge acquisition and administrative employee performance in the studied institutions. It was found that the knowledge acquisition influence the functional capability of administrative employees in higher educational institutions and knowledge acquisition has a high predictive capability for administrative employee performance $(\mathrm{R}=.736)$.
\end{abstract}

Keywords: knowledge acquisition, knowledge sharing, continuous learning, creativeness, sociality, shared experiences

\section{Introduction}

The increased level of demand for quality service delivery has also triggered concern for improved employee performance. The change in work processes resulting from new technological breakthroughs also require that employee functionality in line with such changes is given premium attention. Several conceptualizations however exist in extant literature that has given incisive attention to employee performance. While the early management thought believed that optimal productivity can be attracted from the employee through properly measured work tasks, division of labour, structuring and job design amongst others, the behavioural perspectives stressed relational concern and perhaps extrinsic incentives as a basis for stimulating and sustaining employee performance. Melford (2006) through a critical analysis of the different conceptualization on employee performance had come to a conclusion that the changing times and context have diminished the potency of the existing conceptual /theoretical framework that one served managers in ensuring high employee performance. The implication is there is a dare challenge for further assertion of workplace action either strategic or tactical that will engender improved employee performance for contemporary customer expectation. In line with this position, Prusak (1996) had earlier argued that the only thing that gives organization a competitive edge and sustainability in what it knows, how it uses what it knows and how first it can know something new. From Prusak's position, the human resource has been unarguably noted as the basis for knowing in work organizations (Ahmed, 1998; Edvinsson, 2000; Marr et al., 2003) which also suggest that how they know and the usage of what they know is also important. The today organization is no doubt increasing its guest for intangible asset like knowledge for continued survival and employees are central to this in view of the fact that knowledge is a resource for strategic innovative actions that enhances operational actions. The Nigerian tertiary educational sector with the imposing challenge of quality service delivery due to increase proliferation of universities admission seeking candidates require a quality workforce that has the know-how and the willingness to know something for optimal and improved performance. Wellington (2007) observed that there is poor capacity to serve while there is increased demand for quality service by those to be served and this is a function of poor attitude to enhancing knowledge capacity of the human resource that are structurally positioned to undertake assigned tasks. 
We have earlier noted that earlier thoughts have offered several approach aimed at enhancing performance of the employee but the need for an empirical link between knowledge acquisition practices and employee performance is stressed especially among administrative personnel of universities which we also think is a knowledge institution that should readily provide knowledge for personnel for effectiveness at all levels.

\subsection{Objectives of the Study}

The general purpose of this study is to examine the influence of knowledge acquisition practices and administrative employee performance specifically the objectives aimed areas follows:-

1) To determine the extent to which continuous learning influence administrative employee performance in higher educational institutions.

2) To find the extent to which shared experiences influence administrative employee performance in higher education institutions.

3) To find the extent to which storage practices influence administrative employee performance in higher educational institutions.

4) To determine the extent to which data sources influence administrative employee performance in higher educational institutions.

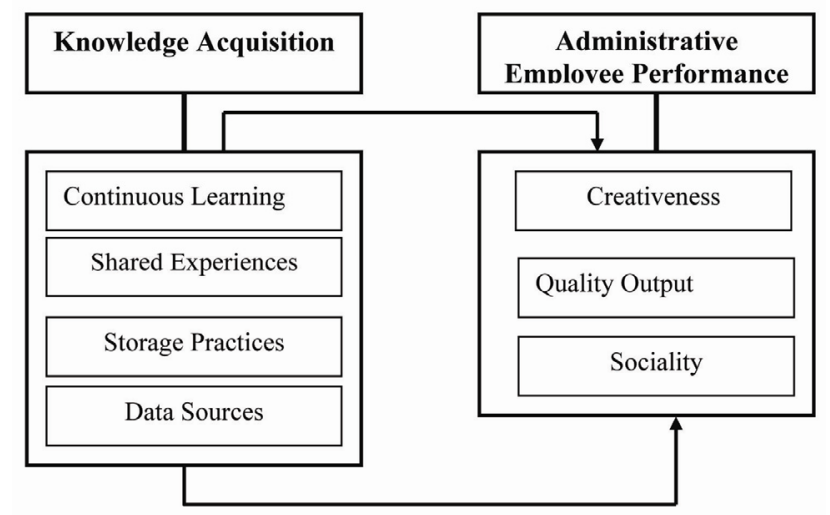

Figure 1. Conceptual framework for the study

\subsection{Significance of the Study}

The study is prompted by the need to ensure the attainment of the primary goals of higher education in term of providing high level manpower for nation building. This is in addition to building capacity and ensuring the sustenance of the existing personnel work skills. The administrative workforce which is central to attainment of all such lofty goals requires that they are substantially provided with needed skills and competencies that facilitate quality service delivery across all levels of work. The results of this study will enable management to craft strategic programmes that will facilitate knowledge acquisition and sharing among workers. Again it will ensure the acquisition of the needed infrastructure that will facilitate knowledge management practices in the institutions. It will further offer the needed pedestal for further works in the area of organizational development.

\section{Literature Review}

\subsection{Knowledge Acquisition}

The changing world of work has strikingly initiated the discourse on knowledge as a critical resource that strategically induce organization performance outcome. The thinking is that the human resource is imbued with knowledge that instigates his ability to contribute and undertake work tasks. Knowledge is the impetus for his acquired skills and competencies. The importance of knowledge has been underscored in strategic management literature therefore its management has assumed same dosage in the discourse (Helfert \& Liberman, 2002; Trispas, 2009). Knowledge management as a process involves acquisition, refinement, storage, transfer and sharing within organization thus representing a dynamic competitive resource as espoused in the knowledge base view of Gilsby, (2007). It has also been defined by Scaborough (2008) that it is the process of creating, acquiring, capturing and sharing knowledge whenever it is found. Egbu (2001) had considered strongly that in all of these processes, the need to acquire it is a strong concern for all members of the organization. Acquiring knowledge 
according to the author is a candidly initiated effort to strategically alter attempt at competitiveness with a view to ensuring dominance among competitors. Billa (2006) opined that knowledge seeking firms are operational string to the extent that they sufficiently share through structural flexibility and infrastructure that facilitate sharing. These positions suggest the premium ascribed to firms ability to acquire knowledge for all purposes.

Prahlad and Hammel (2002) relying on the knowledge based view had noted that competencies are seen as the basis for a company's ability to acquire competitive advantage. They had further observed that employees improved work action in relation to assigned responsibilities is not a function of tangible or extrinsic incentives or the conducive work environment rather, the todays worker characteristically acquire knowledge which constitute the asset that reengineer all work processes towards goals. As earlier noted, the acquisition component of the entire knowledge management process is fundamental as it preceeds other activities in the entire knowledge management spectrum.

Rendenick (2008) had considered knowledge spread among employees as being a significant practice especially within tacit classification of knowledge. The argument put forward here is that since knowledge is in built within the individuals, it will require germane organizational platform created to help in its acquisition. To achieve this Renderick believed that a continuous interaction platform that will help in knowledge sharing and transfer is important for knowledge acquisition and sharing. This is in addition to the authors thinking that the sources from which the individual acquire knowledge and share it is also imperative for quality knowledge that meets the goals of building intellectual capital that is sustainable for competitiveness.

Ewang (2006) noted that to generate employee support for organizational success, knowledge acquisition provides the strategic leverage that is empowering both in psychological and practical context of work. The willingness to acquire and strengthen what is eventually shared as shown in literature had seemingly shown the link between knowledge acquisition and several work outcomes. While these links are empirically biased they have been contextualized within the functions and levels of work structure especially when viewed in the light of responsibility variance that may result from different levels of the organization. Therefore, we hypothesis thus:

\subsection{Employee Performance}

Performance either at the employee or organizational levels has had a robust discourse in management literature (Ghalayani \& Noble, 1996; Kaplan \& Norton, 2001; Robins, 2003; Chenhall, 2005). It is importantly discussed with the organizational ideology of an entity with goal focus therefore the imperative need to assess if such goals are being met or are progressively achieved. A common point arising from the multi positions in literature is the agreement on the multi dimensions that are applicable in expressing performance at the employee and organizational levels (Pannel \& Wright, 1993; Dennison \& Mishra, 1995; Peter \& Crawford, 2004; Lee, 2005; Nagho, 2009). At the employee level of analysis which is the focus in this study, employee performance according to Yakok, (2008) is the expected positive input required at all functional levels which convert to overall organizational performance. It simply means that there is considered and contextualized employee behaviour or input in relation to tasks and responsibilities that are strategically desired by organizations that aptly describes performance for employees. This view also imposes a burden of measurement that will best fit performance for employee so that it is not treated as a vague construct without content. Philemon, (2009) has espoused that in measuring performance at the employee level, much of the attention is on social behaviour. This circumstance subtly shifts from the traditional financial orientation measurement which has hitherto and primarily constitute basis of measurement for the construct. Particularly, Lailya (2004) posits that at the employee level of analysis in the performance debate, a realization of non financial related measure for assessing employee performance will probably be more realistic Garvey, (2010) noted that the changing business times has necessitated broadening the measurement spectrum and measurement should be contextualized especially with the business focus, what management expects from employees and likewise employee perspectives.

The foregoing theoretical positions offer us the leverage of choice of measures for employee performance. In this circumstance, employee performance is viewed from process and behaviour oriented perspectives. Employee performance in this vein is assessed with creativeness and quality output that is expected based on available volume of knowledge that serves the competencies needed to undertake tasks.

\section{Methodology}

The study adopted a positivist philosophical perspective to research inquiry. It simply means that our methodology is quantitative and this guides the way data is generated. In this study, a total of eighteen (18) universities within the South-South, South-East and South-West geo-political zones of Nigeria were used for the study. The study though had the South-South universities primarily in focus, has also considered some other universities from those zones that are very close and have common exchange or linkages with the ones primarily 
investigated. It is believed that these linkages have created platform for common interaction and perhaps promoted knowledge sharing. A total of 468 Administrative employees from the universities were selected from the entire population of 1982 personnel acquired from the establishment units of the different universities (Krejcie \& Morgan, 1978) as presented in Sekaran (2003). We have relied on data from this unit because it was important to know those that are on the level described as administrative personnel which in this instance are those on level 08 upward to the position of deputy registrars.

\section{Regressional Model Specification}

$\mathrm{AEP}=\mathrm{f}(\mathrm{KA})$

Where

$\mathrm{AEP}=\mathrm{CR}, \mathrm{QO}$ and $\mathrm{SOC}$.

$\mathrm{KA}=\mathrm{CL}, \mathrm{SE}, \mathrm{SP}$ and DS.

$\mathrm{CR}, \mathrm{QO}, \mathrm{SOC}=\mathrm{f}(\mathrm{CL}, \mathrm{SE}, \mathrm{SP}$, and DS).

\subsection{Data Collection}

In gathering data for this study, a questionnaire was used as the instrument. For the purpose of enhancing participation and robust data gathering, we had appointed research coordinators across all the universities. They ensured that the respondents were directly contacted and served a copy of the survey instrument. Prior to serving the questionnaire through the research coordinators, we had interaction with some of the unit heads to acquaint them with the objective of the exercise and solicited their support for the research coordinators. The survey instrument was served and participants were given 15 working days to attend to them and the research coordinator retrieved same from them. This approach enhanced the rate of retrieval which was up to $81 \%$ and considered very significant for the study.

\subsection{Measures}

The dimensions of knowledge acquisition as used in this study have been extensively sought from literature. They reflect the volume of literature that has given credence to the continued search for the in-depth understanding of the construct. The knowledge acquisition construct was measured using Ewang (2006). 12 item measurement scale that examined the construct compositely. We had however considered the more expansive scale of Gronror and Scalaby (2009) which was drawn from that of Ewang but considered the independence of the components and had 23 item and which showed a reliability alpha of 0.88 .

For administrative employee performance, we have relied on Lailya, (2004) 16 item scale which was used and validated by Philemon (2009) with a Cronbach alpha of 0.77 . These scales were also drawn on 5 points Likerts scale of $5=$ Strongly Agree to $1=$ Strongly Disagree.

Further, the identification of existing knowledge acquisition mix elements has raised the debate as to whether it is a separate construct from the knowledge management construct as Nahkis (2006) suggested that its mere relabelling. Though the Cronbach alpha value has shown reliability the need to further establish the theoretical composition of knowledge acquisition is considered important therefore we submitted for factor analysis. The factors from the results in Table 1 have shown four main factors that are theoretically related to knowledge acquisition construct. They include continuous learning, shared experiences, storage practices and data sources.

Table 1. Factor loading for knowledge acquisition dimensions

\begin{tabular}{|c|c|c|}
\hline 1 & Continuous Learning & Factor Loading \\
\hline \multirow{11}{*}{2.} & Periodic Seminar & 0.958 \\
\hline & Specialized Training Programmes & 0.666 \\
\hline & Conferences & 0.882 \\
\hline & Exchange Programmes & 0.769 \\
\hline & Peer Reading & 0.913 \\
\hline & Shared Experience & \\
\hline & Cross functional Interaction & 0.885 \\
\hline & Telling Time & 0.711 \\
\hline & Communities of Practice & 0.855 \\
\hline & Informal Discussion & 0.749 \\
\hline & Departmental Reflections & 0.768 \\
\hline
\end{tabular}




\begin{tabular}{lll}
\hline 3. & Storage Practices & \\
& Manual Filing & 0.693 \\
& Electronic filing & 0.841 \\
& & \\
4. Data Sources & 0.904 \\
& Libraries & 0.872 \\
& Internet & 0.853 \\
& Government Depositories & 0.682 \\
\hline
\end{tabular}

\section{Results}

Table 2. Means, standard deviations and bivariate correlations

\begin{tabular}{|c|c|c|c|c|c|c|c|c|c|c|}
\hline & & Mean & Std & 1 & 2 & 3 & 4 & 5 & 6 & 7 \\
\hline 1. & Continuous Learning & 3.78 & 0.76 & 1.0 & & & & & & \\
\hline 2. & Shared Experiences & 3.11 & 0.75 & $.687^{* *}$ & 1.0 & & & & & \\
\hline 3. & Storage Practices & 3.50 & 0.80 & $.596^{* *}$ & $.609^{* *}$ & 1.0 & & & & \\
\hline 4. & Data Sources & 3.38 & 0.79 & $.660^{* *}$ & $.554^{* *}$ & $.560^{* *}$ & 1.0 & & & \\
\hline 5. & Creativeness & 3.57 & 0.94 & $.877^{* *}$ & $.825^{* *}$ & $.825^{* *}$ & $.825^{*}$ & 1.0 & & \\
\hline 6. & Quality Output & 3.32 & 0.81 & $.303^{* *}$ & .089 & $.310^{* *}$ & $.375^{* *}$ & $-.332^{* *}$ & 1.0 & \\
\hline 7. & Sociality & 3.13 & 0.74 & $.288^{* *}$ & $-.219^{*}$ & -.086 & $-.237^{*}$ & $-.252^{* *}$ & -.101 & 1.0 \\
\hline
\end{tabular}

Hypothesis 1 predicted a positive relationship between continuous learning and creativeness quality output and sociality. There was full support for the hypothesis as continuous learning was related to all the measures of administrative employee performance $(\mathrm{r}=.877, \mathrm{p}<0.01 ; \mathrm{r}=.303, \mathrm{p},<0.01$ and $\mathrm{r}=.288, \mathrm{p}<0.01)$.

In the case of Hypothesis 2 which predicted a positive relationship between shared experience and creativeness, quality output and sociality, it has full support for shared experiences and creativeness and quality output but the relationship for sociality was negative but also significant. With the statistic, $\mathrm{r}=.825, \mathrm{P}<0.01 ; \mathrm{r}=.089, \mathrm{P}<0.01$ and $\mathrm{r}=-.219, \mathrm{P}<0.01$ respectively, it shows significant relationship.

In same vein, for data storage practices and administrative employee performance measures, a positive and significant relationship exist with $(\mathrm{r}=.0825, \mathrm{P}<0.01$ and $\mathrm{r}=.310, \mathrm{P}<0.01)$ for creativeness and quality output, it showed support. This was however negative for storage practices and sociality which has $r=-.086, P<0.01$. It was also found that in Hypothesis 4 there was support for the relationship between data sources and creativeness with $\mathrm{r}=0.82, \mathrm{P}<0.01$ but negative and significant with quality output and sociality. They both have $\mathrm{r}=-.375$ and $\mathrm{r}=-.237$ and all at $\mathrm{P}<0.01$. These hypotheses are further examined using the regression model to know degree of variable explanation between the predictor and criterion variables. The tables below show this.

Table 3a. Model summary

\begin{tabular}{lllllll}
\hline Model & $\mathbf{R}$ & $\mathbf{R}^{\mathbf{2}}$ & Adj $\mathbf{R}^{\mathbf{2}}$ & Std Error of Estimates & F change & Sig \\
\hline 1 & 0.736 & 0.541 & .527 & .32179 & 36.084 & 0.05 \\
\hline
\end{tabular}

a. Predictors: (Constant), Continuous Learning, Shared Experiences, Storage Practices, Data Sources.

b. Dependent variable: Administrative Employee Performance

Table 3b. Coefficients

\begin{tabular}{|c|c|c|c|c|c|c|}
\hline \multicolumn{7}{|c|}{ Coefficient @ } \\
\hline \multirow{3}{*}{\multicolumn{2}{|c|}{ Model }} & \multirow{2}{*}{\multicolumn{2}{|c|}{$\begin{array}{l}\text { Unstandardized } \\
\text { Coefficients }\end{array}$}} & \multirow{3}{*}{$\begin{array}{l}\text { Standardized } \\
\text { Coefficients } \\
\text { Beta }\end{array}$} & \multirow[t]{3}{*}{$\mathrm{T}$} & \multirow[t]{3}{*}{ Sig } \\
\hline & & & & & & \\
\hline & & B & Std Error & & & \\
\hline \multirow[t]{5}{*}{1.} & Constant & -1.034 & 0.628 & & -1.648 & 0.102 \\
\hline & Continuous Learning & 0.767 & 0.097 & 0.583 & 7.888 & 0.000 \\
\hline & Shared Experiences & 0.361 & 0.229 & 0.131 & 1.575 & 0.118 \\
\hline & Storage Practices & 0.198 & 0.086 & 0.181 & 2.310 & 0.023 \\
\hline & Data Sources & 0.152 & 0.020 & 0.488 & 2.488 & 0.064 \\
\hline
\end{tabular}

(a) Dependent variable: Administrative Employee Performance. 
The hypotheses were also tested through a regression analysis. The result of the regression analysis of the relationship between knowledge acquisition and administrative employee performance are shown in Table 3a. It also shows the ANOVA of the fitted regression equation, significant with $f$ value 36.084 . This is an indication that the model is a good one; it shows a statistically significant relationship between the variables at $95 \%$ confidence level. The results also show that knowledge acquisition relates with administrative employee performance of tertiary institutions in Nigeria with a coefficient of 0.73 . The $\mathrm{R}^{2}$ statistic shows that the model explained $54 \%$ of the total variability in the AEP. In otherwords $54 \%$ of the criterion variable is explained by the predictor variable. Further, the most important predictor of administrative employee performance from the model result is continuous learning with the beta value, $\beta=0.583$ and $t=7.88$. This was followed by data sources with a beta value, $\beta=0.488$ and $t=2.488$. Storage practices and shared experiences however had beta values of $\beta=0.181$ and 0.131 and $t$ values $=2.310$ and 1.575 respectively.

\section{Discussion of Findings}

The result of the inferential analysis supports the stated hypotheses especially in relation to continuous learning and shared experiences components of the construct. Jafett (2006) in his study on information seeking behaviour of employees in hypa-competitive fast food sector had stressed that continuous learning is the basis for innovative practices that strengthen their ability to compete. Cornell (2012) also correlate continuous learning as a change management strategy with employee commitment. In his study, continuous learning was described as the premise for renewing skills and competencies to undertake tasks. The findings of our study gives empirical support to the association between continuous learning as a knowledge acquiring practice and employee performance Maria (2007) had emphasized that shared experience as a means of acquiring knowledge readily ensures that knowledge beneficiaries are not hindered by structural and technological milieu of work organization. This means that it serves a source of close interaction that maximizes knowledge sharing. In this study, the influence of shared experiences as a means of acquiring knowledge and employee performance in the studied sector is quite illuminating. Lahrda and Gaestrok (2010) have demonstrated in their study that when workers often come together to reminisce on their work experience through 'telling true' practices, it permits a fast approach to acquiring knowledge and our findings have reinforced this position.

Few studies have demonstrated support for storage practices. Though literature had emphasized storage modes as important aspects of the entire process of seeking, preserving and disseminating knowledge among all work members and helping to achieve the goal of competitiveness (Katzenbach, 1998; Ireland et al., 2003; Goldby et al., 2005). The results of this study are indicative of the storage component of knowledge acquisition's ability to influence organizational actions especially in stimulating employee performance. Graener (2003) had discussed the emotional aspect of employee feeling whenever knowledge storage makes it difficult for information retrieval. Although there is lack of empirical evidence linking it directly with employee performance, this study had pushed further on the functionality of storage practices as a way of making knowledge requirement available to optimize employee involvement in strategic tasks.

The relationship between knowledge acquisition and employee performance is also asserted in the data source component of knowledge acquisition. The significance of data source and quality of information is evidenced in literature (Leana \& Buren, 1999; Lin, 2007; Mom et al., 2007). The knowledge management discourse is quite elaborate on data sources as premise for viable information acquisition. The results of this study in relation to data sources as a component of knowledge acquisition and employee performance treated compositely; shows empirical association which suggests that data sources cannot be given peripheral position in the area of employee performance.

In educational institutions, the multiple activities and responsibilities of administrative employee includes facilitating both main and auxiliary services that ensure timely and quality knowledge transfer to students and other knowledge seekers within and outside the universities. In same vein they require sufficient knowledge that strengthens their capacity to undertake such roles. From the study results, their ability to be creative and ensure quality output is largely predicted by the extent to which knowledge is acquired by the administrative employees. The findings here give support to Lailya (2004) position on employee knowledge level and functionality. It also underscores Chentall (2005) theoretical position on learning organization. The author had argued that learning is a strategic approach by organizations to be functionally innovative as the strike within their markets to be competitive and positioned. Administrative employees in educational institution require same dosage of knowledge to be creative and helping to achieve the long-term goals of the institutions. 
The findings generally, provide evidence that knowledge acquisition practices of the organization can be considered strategic for influencing employees to higher level performance. Essentially, the findings provides support for the thinking that knowledge acquisition is a major behavioural expression that represents workplace culture therefore the mechanism that promotes it towards ensuring optimal employee performance should be encouraged.

\section{Conclusion/Policy Implication}

The study from the on-set had set out to examine the nature of relationship between knowledge acquisition practices and administrative employee performance. From the data generated and analysed, the results have shown a significant relationship between knowledge acquisition practices and administrative employee performance. With the degree of significance it has also shown that knowledge acquisition is a predictor of administrative employee performance in terms of creative work attitude, quality output and sociality. This simply means that tertiary institutions with knowledge seeking culture will improve employee performance. What this means importantly is attention of the management of tertiary educational institutions be drawn to knowledge acquisition as a strategic activity for organizations that require a qualitative and creative workforce that is also socially responsive to the work community. Educational institutions are centres of knowledge creation and dissemination therefore should have a functional administrative workforce that is equipped with sufficient knowledge that will facilitate both support and primary services rendered to all stakeholders. The findings of the study strongly draws attention of both strategic management team and administrative employees alike to ensuring that continuous learning practice should be encouraged perhaps not just as a means of acquiring knowledge but also enhancing quality knowledge acquisition through creative approaches that ensures and sustains the quality. Structural flexibilities in the educational institutions should be encouraged as a means by ensuring that employees are various levels of work can commonly interact and share experiences that promote knowledge acquisition across functions and levels. Another major issue that has been underscored from the study is that of data sources. Educational institutions should be mindful of use of qualitative sources that do not adulterate the essence of knowledge that is acquired rather sources that are value-added to existing knowledge stock should be explored. It has also emphasized the need for policy makers in educational institutions to be attentive to the entire knowledge management process with a view to ensuring an organizational climate that guarantee acquisition of knowledge for improved employee performance. The study outcome has helped in broadening the understanding of knowledge management practices that is hitherto analysed at the macro level. The micro analytical approach adopted is yet rewarding as it helps management in identifying the appropriate platform that will help in enhancing knowledge acquisition among work members.

\section{Suggested for Further Research}

There is an imposing need to broaden the understanding of the work variables that are capable of enhancing the performance capabilities of employees in work organizations. It has been hitherto adduced that employees in low ebb economies are essentially instigated to high performance with recourse to financial incentives. This thinking which scarcely provides the performance discourse with desired end point require that further works be done in the knowledge management area with a view to finding out how each of the activities is likely to influence desired performance behaviour. Aside acquisition approaches, sharing culture require examination especially in other work cultures and find out how it affects performance both at the macro and micro levels of organization.

\section{References}

Ahmed, P. K. (1998). Culture and Climate for Innovation. European Journal of Innovation Management, 1(1), 30-43. http://dx.doi.org/10.1108/14601069810199131

Billa, J. O. (2006) Motivating for Compliance in Knowledge Management Scheme for on-the-Shop Floor Employees. Journal of Management, 15(7), 92-108.

Cheuhall, R. H. (2005). Integrative Strategic Performance Measurement System, Strategic Alignment of Manufacturing, Learning and Strategic Outcomes: An Exploratory Study. Accounting, Organizations and Society, 30(5), 395-422. http://dx.doi.org/10.1016/j.aos.2004.08.001

Cornell, C. E. (2012). Change Management: Problem and Solutions. Journal of Organizational Development, 9(6), 111-127.

Edvinson, L. (2000). The Knowledge Management Model. Journal of Knowledge Management, 4(14), 356-364.

Ewang, F. P. (2005). Intellectual Capital Fit among Medium Organizations. Journal of Innovation Science, 42(8), 773-792. 
Garvey, S. (2010). Knowledge as an Asset: Applicability in Large Firms. Journal of Management, 18(7), 218-232.

Ghalayani, A. M., \& Noble, J. S. (1996). The Changing Basis of Performance Measurement. International Journal of Operations Production Management, 16(8), 53-80.

Gilsby, O. (2007). Intellectual Capital Management and Competitiveness among ICT Support Firms. Journal of Information Technology, 7(11), 67-83.

Goldsby, M. G., Kuratko, D. F, \& Bishop, J. W. (2005). Entrepreneurship and Fitness: An Examination of Rigorous Exercise and Goal Attainment among Small Business Owners. Journal of Small Business Management, 43(1), 78-92. http://dx.doi.org/10.1111/j.1540-627X.2004.00126.x

Graener, C. J. (2003). The Improving Challenge of Moving Knowledge Elsewhere. Knowledge Management, 11(3), 312-318.

Gronror, O., \& Scalaby, F. N. (2009). Improving Productivity of Service Workers: The Knowledge Question. Journal of Knowledge Management and Innovation Science, 10(3), 69-87.

Helfat, C. E., \& Liberman, M. B. (2002). The Birth of Capabilities: Market Entry and the Importance of Pre-History. Industrial and Corporate Change, 11(4), 725-760. http://dx.doi.org/10.1093/icc/11.4.725

Ireland, R. D, Hitt, M. A., \& Simon, D. (2003). A Model of Strategic Entrepreneurship: The Construct and its Dimensions. Journal of Management, 29, 963-989. http://dx.doi.org/10.1016/S0149-2063(03)00086-2

Juffet, O. O. (2006). Managing Intellectual Capital and Competitiveness. Journal of Knowledge Management, 16(12), 48-64.

Kaplan, R. S., \& Norton, D. P. (2001). The Strategy Focused Organization: How Balanced Scorecard Thrive in New Business Environment. Boston, MA: Harvard Business School Press.

Katzembach, S. (1998). Team at the Top: Unleashing the Potential of Both Teams and Individual Leaders. Harvard School Press, Boston MA.

Lahrda, J., \& Gaestrok, D. (2010). The Knowledge Spring. Journal of Knowledge Service, 9(6), 71-84.

Lailya, M. (2004). A Framework for Knowledge Management. Lagos: Lamdu Pub Co.

Leana, C. R., \& Van Buren, H. J. (1999). Organizational Social Capital and Employment Practices. Academy of Management Review, 24, 538-555.

Lee, Y. C. (2005). Knowledge Value Chain: Revisiting the Dynamics. Journal of Knowledge Management, 16(6), 331-349.

Lin, H. F. (2007). Effects of Extrinsic and Intrinsic Motivation on Employee Knowledge Sharing Intentions. Journal of Information Science, 33(2), 135-149. http://dx.doi.org/10.1177/0165551506068174

Maria, I. (2007). Reviewing Knowledge Management Perspective in Hi-Tech Sector. Journal of Management Studies, 17(3), 79-93.

Marr, B., Giovanni, S., \& Neely, A. (2003). Assessing Strategic Knowledge Assets in E-Business. International Journal of Business Performance Management, 4(4), 279-295.

Melford, A. A. (2006). Knowledge Management Insights. Lagos: Belkan Pub.

Mom, I. J., Van Den Bosch, F. A., \& Volberda, H. W. (2007). Investigating Manager's Exploration and Exploitation Activities. The Influence of Top-Down, Bottom-Up and Horizontal Knowledge Inflows. Journal of Management Studies, 44(6), 910-931. http://dx.doi.org/10.1111/j.1467-6486.2007.00697.x

Nagho, P. L. (2009). Knowledge Asset and Firm Performance in a Transition Economy. Journal of Administration, 16(12), 607-618.

Nakhis, G. L. (2006). Increasing Knowledge Space of Competitiveness. Management Science Journal, 4(2), 17-33.

Parnell, J. A., \& Wright, P. (1993). Generic Strategy and Performance: An Empirical Test of the Miles and Snow Typology. British Journal of Management, 4, 29-36. http://dx.doi.org/10.1111/j.1467-8551.1993.tb00159.x

Philemon, K. (2006). Knowledge Codification and Process Capital Infrastructures. Knowledge Management Journal, 17(7), 413-444. 
Prahald, C. K., \& Hammel, G. (1990). The Core Competence of the Corporation. Harvard Business Review, 68(3), 78-91.

Prusak, L. (1997). Knowledge in Organizations. Washington: Butterworth -Heinemann.

Renderick, B. N. (2008). Behavioural Surveillance in Work Organizations. Ibadan: University Press.

Robins, J. (2003). Organizational Learning: Implication for Strategic Renewal Project in Large Firms. Journal of Innovation and Organizational Development, 23(7), 412-436.

Scaborogh, H. (2008). Knowledge Management: A Research. London: Bearly Pub.

Scarbough, H., Swan, J., \& Prestone, J. (1999). Knowledge Management. Plymouth, Devon, Plymbridge Distributors.

Trispas, M. (2009). Technology, Identity, and Inertia through the lens of the Digital Photography Company. Organization Science, 20(2), 441-460. http://dx.doi.org/10.1287/orsc.1080.0419

Wellington, D. S. (2007). Measuring Quality in Knowledge Management. Knowledge Management Journal, 2(8), $15-22$.

Yakok, A. A. (2008). The Criticality of Knowledge Assets. Intellectual Capital Management Journal, 3(2), 143-154.

\section{Copyrights}

Copyright for this article is retained by the author(s), with first publication rights granted to the journal.

This is an open-access article distributed under the terms and conditions of the Creative Commons Attribution license (http://creativecommons.org/licenses/by/3.0/). 